11 Robinson PD, Turner M, Brown NJ, et al. Procedures to improve the repeatability of forced oscillation measurements in school-aged children. Respir Physiol Neurobiol 2011; 177: 199-206.

12 American Thoracic Society, European Respiratory SocietyATS/ERS statement: raised volume forced expirations in infants: guidelines for current practice. Am J Respir Crit Care Med 2005; 172: 1463-1471.

13 Hall GL, Stanojevic S, Beasley R, et al. Revised historical spirometry reference ranges are reflective of contemporary healthy spirometry values. Eur Respir J 2008; 32 Suppl. 52:382s-383s.

14 Subbarao P, Stanojevic S, Brown M, et al. Lung clearance index as an outcome measure for clinical trials in young children with cystic fibrosis: a pilot study using inhaled hypertonic saline. Am J Respir Crit Care Med 2013; 188: 456-460.

15 Daviskas E, Anderson SD, Eberl S, et al. The 24-h effect of mannitol on the clearance of mucus in patients with bronchiectasis. Chest 2001; 119: 414-421.

\title{
Estimation of post-operative forced expiratory volume by functional respiratory imaging
}

\author{
To the Editor:
}

Surgical resection is a potential curative therapy for patients with early-stage non-small cell lung cancer (NSCLC). Comorbid chronic obstructive pulmonary disease (COPD) is frequently present in these patients [1], stressing the importance of an accurate estimation of post-operative (po) forced expiratory volume in $1 \mathrm{~s}(\mathrm{FEV} 1)$ [2]. A predicted poFEV1 $\left(\mathrm{PpoFEV}_{1}\right)$ must be calculated whenever the pre-operative FEV1 or diffusing capacity for carbon monoxide is $<80 \%$ predicted [3]. The anatomic segment method (ASM) and perfusion scintigraphy (QS) are often used for this prediction $[4,5]$. Both are known to underestimate the poFEV 1 in a substantial fraction of patients, resulting in the possible exclusion from resection of a borderline operable patient $[6,7]$. This stresses the need for a more precise tool to estimate poFEV1.

Current imaging techniques (computed tomography (CT), magnetic resonance imaging and four-dimensional CT) allow a patient-specific description of spatial differences in lung mechanics and this information might lead to a better prediction of poFEV1 [8]. Functional respiratory imaging (FRI) has added functionality to CT data by means of computational fluid dynamics (CFD) airflow calculations $[9,10]$. FRI has been used in different settings and populations [11-13]. This study investigated whether FRI can be used to predict poFEV1, using data at baseline and after virtual resection, and compared the predictive accuracy of FRI with those of ASM and QS.

This single-centre, prospective pilot study enrolled consecutive patients with early-stage NSCLC that was considered resectable and scheduled for lobectomy/pneumonectomy. Eligible subjects performed spirometric manoeuvres according to the American Thoracic Society/European Respiratory Society standards [14] before and after resection. PpoFEV1 using ASM and QS were calculated according to previous reports [4-7]. Before surgery, all patients also underwent breath-hold spirometry and low-dose chest CT scans at two different lung levels, i.e. total lung capacity (TLC) and residual volume (RV). Institutional review board approval was obtained and a written informed consent was provided by all patients.

From both RV and TLC scans, a reconstruction was made of different lung lobes to assess the changes in lobar volume from RV to TLC (lobar expansion (EXP)). From the TLC scan, the airway tree was segmented up to the point where the CT image quality no longer allowed for distinction of bronchi. CFD calculations provided flow properties within the reconstructed airway trees. Image processing and steady CFD calculations (assuming 25-L. $\mathrm{min}^{-1}$ tracheal flow with flow split ratios according to the relative lobar EXP) on a noncompliant airway model were performed according to the reports by DE BACKER and co-workers $[9,10]$ to estimate pre-operative airway resistance. Virtual resection was performed by the removal of the airways leading to the lung/lobes targeted for lung resection. Again, steady CFD calculations (flow split ratios according to the relative lobar EXP of the nonresected parts) were carried out to estimate post-operative airway resistance. 
PpoFEV1 using FRI (PpoFEV1 $1_{\mathrm{FRI}}$ ) was estimated using the equation:

$$
\operatorname{PpoFEV}_{\mathrm{FRI}}=\mathrm{FEV}_{1} \text { pre }\left(1-\frac{\left(1-\sqrt[4]{\frac{\mathrm{i} \text { Raw }_{\text {virtual }}}{\mathrm{i} \text { Raw }_{\text {pre }}}}\right) \text { EXPresected }}{\text { EXPlungs }}\right)
$$

Where $\mathrm{FEV}_{1}$ pre is the pre-operative $\mathrm{FEV} 1, \mathrm{i} \mathrm{Raw}_{\text {pre }}$ is the resistance of the pre-operative airway model, $\mathrm{i} R \mathrm{aw}_{\text {virtual }}$ is the resistance after virtual resection, EXPlungs is the expansion of both lungs and EXPresected is the expansion of the lobe or lung that is planned for resection.

This equation looks very similar to the ASM and QS formulas [4]. It is based on the theory that the total volume of air that can go into the lungs will be reduced by the resected part. However, the airway tree is also affected by the surgery and a compensation factor related to a simulated change in airway resistance is taken into account.

Variables were tested for normality using a Shapiro-Wilk test and homogeneity of variance was determined using a F-test. Differences between the poFEV1 and PpoFEV1 values were assessed using a paired t-test. Furthermore, linear models were created to check whether the observed differences were due to a constant bias or if a slope could be observed. These models were validated with respect to skewness, kurtosis, link function and heteroscedasticity.

Between June 2010 and February 2012, 23 patients underwent measurement of FEV $1_{\text {pre }}$ and poFEV 1 by spirometry, and PpoFEV1 was calculated by ASM, QS and FRI. Nine participants either dropped out due to sublobar or no resection $(n=5)$ or were lost in follow up ( $n=4$, of whom one died before follow-up). Data from 14 patients were available: eight males and six females with a median age of 63 (51-73) years, of whom six patients had COPD; their median (range) $\mathrm{FEV}_{1}$ pre was 2.49 (1.66-4.07) $\mathrm{L}$ and median actual poFEV1 was 2.1 (1.21-3.21) L. No patient suffered from an obstructive tumour that produced lung atelectasis.

Significant differences were found between poFEV 1 and PpoFEV1 by ASM (mean \pm SD $345 \pm 278 \mathrm{~mL}, \mathrm{p}<0.001$ ) and QS $(206 \pm 239 \mathrm{~mL}, \mathrm{p}=0.007)$. No difference was found between poFEV1 and PpoFEV1 by FRI (18 $\pm 220 \mathrm{~mL}, \mathrm{p}=0.767)$. The linear fit between poFEV1 and PpoFEV1 showed that both ASM and QS had a slope of $1.06\left(\mathrm{R}^{2}=0.77, \mathrm{p}<0.001\right)$ and $1.10\left(\mathrm{R}^{2}=0.84, \mathrm{p}<0.001\right)$, respectively, whilst FRI had a slope $<1\left(0.98 ; \mathrm{R}^{2}=0.86\right.$, $\mathrm{p}<0.001$ ). ASM underestimated poFEV1 in 13 out of 14, QS in 13 out of 14 and FRI in seven out of 14 cases.

In this study, PpoFEV1 $1_{\mathrm{FRI}}$ was compared with two current standard techniques. Holvoet et al. [7] reported that ASM underestimated poFEV1 by $350 \mathrm{~mL}$ and QS by $200 \mathrm{~mL}$. Our trial showed very comparable results, with a mean error of $345 \mathrm{~mL}$ for ASM, $206 \mathrm{~mL}$ for QS and $18 \mathrm{~mL}$ for FRI. Although the FRI formula is based on the same principle as ASM and QS, it is thought that the better prediction is due to the fact that patient-specific, regional differences in airway resistance (via $\mathrm{i} R \mathrm{aw}$ ) and tissue compliance (via EXP) are accounted for.

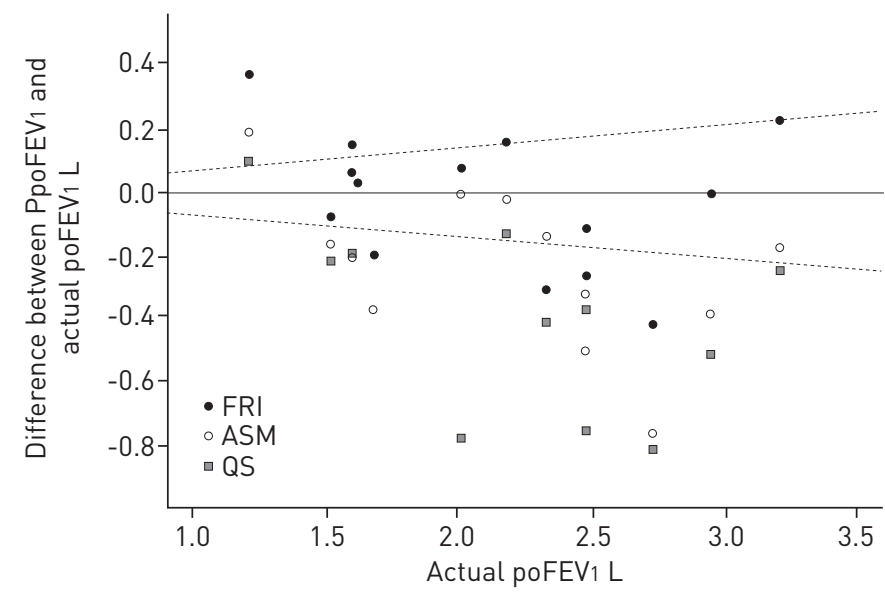

FIGURE $1 \mathrm{~A}$ plot of the difference between the predicted $(\mathrm{P})$ post-operative (po) forced expiratory volume in $1 \mathrm{~s}\left(\mathrm{FEV}_{1}\right)$ and the actual poFEVı against the actual poFEV1. Points above the solid line represent over-prediction of poFEV1. The dotted lines represent the $6.8 \%$ coefficient of repeatability of FEV1. FRI: functional respiratory imaging; QS: perfusion scintigraphy; ASM: anatomic segment method. 
It can be argued that the FRI prediction leads to more overestimation. When taking into account the $6.8 \%$ coefficient of repeatability of FEV1 [15], PpoFEV1 $1_{\mathrm{FRI}}$ is indeed overestimating the actual poFEV1 in three out of 14 patients (versus one out of 14 for ASM and QS) (fig. 1). However, a more precise model is advantageous as the main goal is to predict poFEV1 as well as possible. An accurate model (slope close to 1) can be updated with a safety factor (adding a constant to equation) in order to minimise the risk of adverse events in patients.

Another possibility is to improve the equation for prediction further by incorporating additional imaging based parameters such as quantitative scores for air trapping and emphysema. To further improve PpoFEV $_{\text {FRI }}$, we are developing a flow model that accounts for dynamic change in the position of the airways when undertaking the virtual resection; for example, accounting for how the right middle and lower lobes swing up after resecting the right upper lobe.

Weaknesses of this series are its small size and the fact that its patients had a rather high $F E V 1_{\text {pre }}$ $(>1.66 \mathrm{~L})$ and, hence, do not represent the at-risk population. Multicentre confirmation in a larger cohort of patients with more severely impaired FEV1 is needed. Furthermore, comparison to other (image-based) predictive methods could be of interest.

In this series, FRI was a superior predictor of actual poFEV1 in resected lung cancer patients compared with ASM and QS.

Annelies Janssens ${ }^{1}$, Wim Vos $^{2}$, Cedric Van Holsbeke ${ }^{2}$, Paul Van Schil ${ }^{3}$, Ellie Oostveen ${ }^{4}$, Jan De Backer ${ }^{2}$, Laurens Carp ${ }^{5}$, Annemie Snoeckx ${ }^{6}$, Wilfried De Backer ${ }^{4}$ and Jan P. van Meerbeeck ${ }^{1}$

${ }^{1}$ Thoracic Oncology, Antwerp University Hospital, Edegem, Belgium. ${ }^{2}$ Fluidda nv, Kontich, Belgium. ${ }^{3}$ Thoracic and Vascular Surgery, Antwerp University Hospital, Edegem, Belgium. ${ }^{4}$ Respiratory Medicine, Antwerp University Hospital, Edegem, Belgium. ${ }^{5}$ Nuclear Medicine, Antwerp University Hospital, Edegem, Belgium. ${ }^{6}$ Radiology, Antwerp University Hospital, Edegem, Belgium.

Correspondence: Wim Vos, Fluidda nv, Groeningenlei 135, 2550 Kontich, Belgium. E-mail: wim.vos@fluidda.com

Received: April 042014 | Accepted after revision: Nov 042014 | First published online: Dec 232014

Conflict of interest: Disclosures can be found alongside the online version of this article at erj.ersjournals.com

\section{References}

1 Young RP, Hopkins RJ, Christmas T, et al. COPD prevalence is increased in lung cancer, independent of age, sex and smoking history. Eur Respir J 2009; 34: 380-386.

2 Brunelli A, Xiumé F, Refai M, et al. Evaluation of expiratory volume, diffusion capacity, and exercise tolerance following major lung resection: a prospective follow-up analysis. Chest 2007; 131: 141-147.

3 Brunelli A, Charloux A, Bolliger CT, et al. ERS/ESTS clinical guidelines on fitness for radical therapy in lung cancer patients (surgery and chemo-radiotherapy). Eur Respir J 2009; 34: 17-41.

4 Brunelli A, Kim AW, Berger KI, et al. Physiologic evaluation of the patient with lung cancer being considered for resectional surgery: diagnosis and management of lung cancer, 3rd ed: American College of Chest Physicians evidence-based clinical practice guidelines. CHEST 2013; 143: e166S-e190S.

5 van Tilburg PM, Stam H, Hoogsteden HC, et al. Pre-operative pulmonary evaluation of lung cancer patients: a review of the literature. Eur Respir J 2009; 33: 1206-1215.

6 Bolliger CT, Gückel C, Engel H, et al. Prediction of functional reserves after lung resection: comparison between quantitative computed tomography, scintigraphy, and anatomy. Respir Int Rev Thorac Dis 2002; 69: 482-489.

7 Holvoet T, van Meerbeeck JP, Van De Wiele C, et al. Quantitative perfusion scintigraphy or anatomic segment method in lung cancer resection. Lung Cancer Amst Neth 2011; 74: 212-218.

8 Ohno $\mathrm{Y}$, Koyama H, Nogami M, et al. State-of-the-art radiological techniques improve the assessment of postoperative lung function in patients with non-small cell lung cancer. Eur J Radiol 2011; 77: 97-104.

9 De Backer JW, Vos WG, Vinchurkar SC, et al. Validation of computational fluid dynamics in CT-based airway models with SPECT/CT. Radiology 2010; 257: 854-862.

10 De Backer JW, Vos WG, Gorlé CD, et al. Flow analyses in the lower airways: patient-specific model and boundary conditions. Med Eng Phys 2008; 30: 872-879.

11 Vos W, De Backer J, Poli G, et al. Novel functional imaging of changes in small airways of patients treated with extrafine beclomethasone/formoterol. Respir Int Rev Thorac Dis 2013; 86: 393-401.

12 De Backer W, Vos W, Van Holsbeke C, et al. The effect of roflumilast in addition to LABA/LAMA/ICS treatment in COPD patients. Eur Respir J 2014; 44: 527-529.

13 De Backer LA, Vos W, De Backer J, et al. The acute effect of budesonide/formoterol in COPD: a multi-slice computed tomography and lung function study. Eur Respir J 2012; 40: 298-305.

14 Miller MR, Hankinson J, Brusasco V, et al.. Standardisation of spirometry. Eur Respir J 2005; 26: 319-338.

15 Oostveen E, Boda K, van der Grinten CP, et al. Respiratory impedance in healthy subjects: baseline values and bronchodilator response. Eur Respir J 2013; 42: 1513-1523. 